\title{
Numerical Modeling and Simulation of Wave Impact of a Circular Cylinder during the Submergence Process
}

\author{
Xiaozhou Hu, Yiyao Jiang, and Daojun Cai \\ College of Mechanical and Electrical Engineering, Central South University, Changsha 410083, China \\ Correspondence should be addressed to Xiaozhou Hu; smallboathu@163.com
}

Received 19 April 2017; Revised 12 August 2017; Accepted 2 October 2017; Published 3 December 2017

Academic Editor: Dimitrios E. Manolakos

Copyright (C) 2017 Xiaozhou Hu et al. This is an open access article distributed under the Creative Commons Attribution License, which permits unrestricted use, distribution, and reproduction in any medium, provided the original work is properly cited.

\begin{abstract}
Wave slamming loads on a circular cylinder during water entry and the subsequence submergence process are predicted based on a numerical wave load model. The wave impact problems are analyzed by solving Reynolds-Averaged Navier-Stokes (RANS) equations and VOF equations. A finite volume approach (FV) is employed to implement the discretization of the RANS equations. A two-dimensional numerical wave tank is established to simulate regular ocean waves. The wave slamming problems are investigated by deploying a circular cylinder into waves with a constant vertical velocity. The present numerical method is validated using other numerical or theoretical results in accordance with varying free surface profiles when a circular cylinder sinks in calm water. A numerical example is given to show the submergence process of the circular cylinder in waves, and both free surface profiles and the pressure distributions on the cylinder of different time instants are obtained. Time histories of hydrodynamic load on the cylinder during the submergence process for different wave impact angles, wave heights, and wave periods are obtained, and results are analyzed in detail.
\end{abstract}

\section{Introduction}

Wave impact problem is of great interest in the marine and offshore industries, especially for subsea working systems which are widely used in such applications as marine resource development and utilization, maritime exploration and survey; the important problem which needs to be solved before their proper operations is to accurately study the phenomenon of offshore structures impacting ocean wave and the following submergence process. The process of subsea structures lowering through wave zone accompanies the interaction between the air, wave, and the solid body, which is a complicated fluid-solid problem, involving consideration of time-varying hydrodynamic forces (slamming, drag, inertia, and buoyancy) and time-varying waves. In hostile ocean conditions, these forces can result in significant localized and even catastrophic structural damage on structures ranging from deployed structures to deploying equipment and heave compensator systems and so forth. Therefore, the accurate prediction of wave slamming loads and time histories of hydrodynamic force, as well as the sensitivity of these loads to wave parameters, is of significant importance.
Researches on water entry and wave impact problems were firstly carried out by Karman [1], who studied loads on seaplane floats shaped as wedges during water entry. Wagner developed methods of Karman by taking into account the piled-up water surface along the side of the body [2].

For a rigid cylinder, pioneering studies applied several different methods, including flat plate theories, generalized Wagner theory [3], boundary element method (BEM) [4, 5], and Constrained Interpolation Profile (CIP) method [6, 7]. In recent years, researchers applied other computational fluid dynamics (CFD) methods to this field. For example, Zhang et al. numerically simulated the water entry of a cylinder based on Lattice Boltzmann Method (LBM) [8]. Vandamme et al. simulated water entry and exit of a cylinder with a weakly compressible smoothed particle hydrodynamics (SPH) method [9]. Skillen et al. used SPH method to investigate the motion of a circular cylinder dropping onto initially still water numerically [10]. Gu et al. simulated water impact problem of a semicircular cylinder with the free surface captured using level set method [11]. Nguyen et al. studied water entry of a circular cylinder by integrating a moving Chimera grid method to a preconditioned 
Navier-Stokes solver [12]. Peng and Wei simulated the water entry of a circular cylinder based on a CIP method with the parallel algorithm [13]. Iranmanesh and PassandidehFard numerically investigated water entry of a horizontal circular cylinder for low Froude numbers by the combination of the fast-fictitious-domain method and the volume-offluid (VOF) technique [14]. NAIR and TOMAR employed an incompressible Smoothed Particle Hydrodynamics (ISPH) method to simulate water entry of 2D circular cylinders [15]. Aristodemo et al. performed numerical study on waveinduced forces of submerged circular cylinders by $\mathrm{SPH}$ method [16]. Advances in computer technology and CFD have made it possible to use commercial CFD codes to solve wave impact problem. For example, Mnasri et al. used Fluent code with a moving grid to analyze the free surface evolution induced by one or two moving cylinders [17]. Chen et al. studied water entry of a horizontal cylinder based on VOF method by Fluent [18]. Ghadimi et al. utilized FLOW-3D code to study the water entry of a circular cylinder and conducted a comparison between the linear and nonlinear solutions [19]. Tassin et al. investigated water impact problem of a body with time-varying shape by CFD code OpenFOAM [20]. Larsen used the CFD code STAR-CCM+ to calculate impact loads on circular cylinders during water entry [21].

This work is devoted to investigate the complex interaction between a circular cylinder and waves during the submergence process. Firstly, both governing equations and boundary conditions are outlined; to study the interaction between wave and cylinders, a numerical wave tank is established, and numerical wave generation and absorption method are presented. Secondly, snapshots of the simulation of calm water entry of a circular cylinder are compared with those of experiments by previous researches. Then, numerical simulations of a circular cylinder impact with waves are conducted, and free surface profiles of different time instants of submergence process are shown. Finally, slamming loads on the circular cylinder are computed, and influence of wave parameters is discussed.

\section{The Numerical Method}

2.1. Governing Equations. In this work, governing equations for the CFD calculations are RANS equations for homogeneous, incompressible fluid flows, and they are written as follows:

$$
\begin{aligned}
& \frac{\partial \bar{u}_{i}}{\partial x_{i}}=0 \quad(i=1,2) \\
& \frac{\partial\left(\rho \bar{u}_{i}\right)}{\partial t}+\frac{\partial\left(\rho \bar{u}_{i} \bar{u}_{j}\right)}{\partial x_{i}}=-\frac{\partial \bar{p}}{\partial x_{i}} \\
&+\frac{\partial}{\partial x_{j}}\left[\mu\left(\frac{\partial \bar{u}_{i}}{\partial x_{j}}+\frac{\partial \bar{u}_{j}}{\partial x_{i}}\right)\right] \\
&+\frac{\partial}{\partial x_{j}}\left(-\rho \bar{u}_{i}^{\prime} \bar{u}_{j}^{\prime}\right)+\rho \bar{f}_{i},
\end{aligned}
$$

where $i, j=1,2$ for two-dimensional flows; $\bar{u}_{i}$ is the average velocity of $i$ th coordinate axis; $\rho$ is the density; $\bar{p}$ is the average pressure; $\mu$ is the dynamic viscous coefficient; $\bar{f}_{i}$ is the average body force; $-\rho \bar{u}_{i}^{\prime} \bar{u}_{j}^{\prime}$ is the Reynolds stress.

$$
\begin{aligned}
\frac{\partial(\rho k)}{\partial t}+\frac{\partial\left(\rho k \bar{u}_{j}\right)}{\partial x_{i}}= & \frac{\partial}{\partial x_{j}}\left[\left(\mu+\frac{\mu_{t}}{\sigma_{k}}\right) \frac{\partial k}{\partial x_{j}}\right]+\rho G_{k} \\
& -\rho \varepsilon \\
\frac{\partial(\rho \varepsilon)}{\partial t}+\frac{\partial\left(\rho \varepsilon \bar{u}_{j}\right)}{\partial x_{i}}= & \frac{\partial}{\partial x_{j}}\left[\left(\mu+\frac{\mu_{t}}{\sigma_{\varepsilon}}\right) \frac{\partial k}{\partial x_{j}}\right] \\
& +\frac{\varepsilon}{k}\left(C_{\varepsilon 1} \rho G_{k}-C_{\varepsilon 2} \rho \varepsilon\right) \\
\mu_{t}= & \frac{C_{\mu} \rho k^{2}}{\varepsilon}, \\
G_{k}= & \frac{\mu_{t}}{\rho}\left(\frac{\partial \bar{u}_{i}}{\partial x_{j}}+\frac{\partial \bar{u}_{j}}{\partial x_{i}}\right) \frac{\partial \bar{u}_{i}}{\partial x_{j}}
\end{aligned}
$$

where $k$ is the turbulence kinetic energy; $\varepsilon$ is the dissipation rate of turbulence kinetic energy; $\mu_{t}$ is the eddy viscosity; $G_{k}$ is the turbulent energy production.

The empirical coefficients in (2) are given as follows [22]:

$$
\begin{aligned}
C_{\mu} & =0.09, \\
C_{\varepsilon 1} & =1.44, \\
C_{\varepsilon 2} & =1.92, \\
\sigma_{k} & =1.0, \\
\sigma_{\varepsilon} & =1.3 .
\end{aligned}
$$

The complex free surface is tracked by the VOF method, and to accomplish the capturing of the interface between the air phase and the water phase, a continuity equation for the fraction of volume of water is solved, which has the following form:

$$
\frac{\partial a_{w}}{\partial t}+u_{i} \frac{\partial\left(a_{w}\right)}{\partial x_{i}}=0 .
$$
by

The sum of the volume fraction of water and air is given

$$
a_{w}+a_{a}=1
$$

where $a_{w}$ and $a_{a}$ are the volume fraction of water and air in each cell, respectively.

2.2. Boundary Conditions. To solve governing equations, it is necessary to specify appropriate boundary conditions at all boundaries of the domain. The boundary conditions which need to be satisfied are as follows: (1) the kinematic and dynamic free surface conditions at the free surface and (2) 


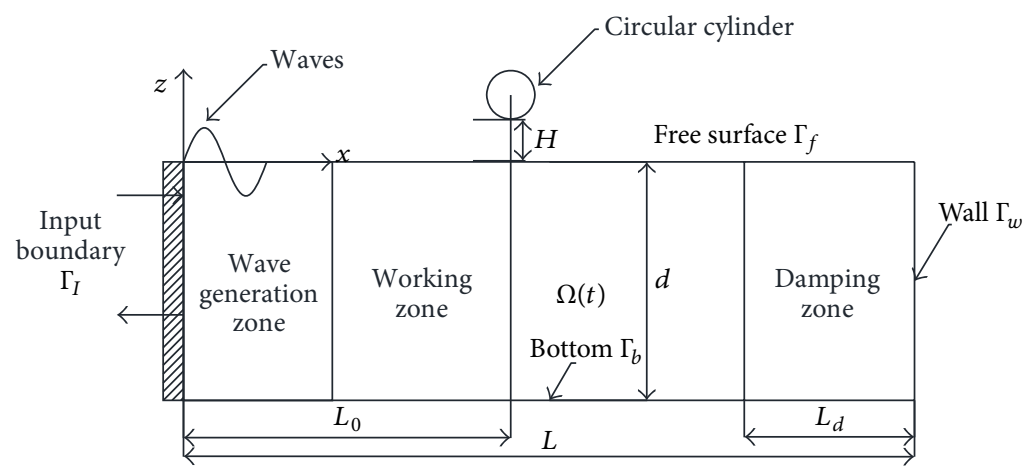

FIGURE 1: Numerical wave tank and a moving circular cylinder.

the no-slip boundary condition at the tank bottom and the rigid body and (3) to investigate the dynamic problem during a circular cylinder lowering through wave zone, a 2D numerical wave tank is utilized. The left wall boundary is a wave-maker, while the right part of the domain is a damping zone, as shown in Figure 1.

2.3. Wave Generation Method and Numerical Wave Dissipation Beach. In order to investigate wave loads on a circular cylinder during its crossing air-water interface, it is necessary to establish a numerical wave tank. In this paper, a piston type wave-maker is utilized to simulate ocean waves, and a sketch of a numerical wave tank with a piston wave-maker located at the left boundary of the domain is illustrated in Figure 1. tion:

The plunger moves horizontally with a sinusoidal func-

$$
X(t)=\frac{X_{0}}{2} \sin \omega t
$$

where $X_{0}$ is the maximum displacement of plunger and $\omega$ is the angular frequency. Then the free surface displacement is given by

$$
\begin{gathered}
\eta(x, t)=\frac{X_{0}}{2}\left(\frac{4 \sinh ^{2} k d}{2 k d+\sinh 2 k d} \cos (k x-\omega t)\right. \\
\left.+\sum_{n=1}^{\infty} \frac{4 \sin ^{2}\left(k_{n} d\right)}{2 k_{n} d+\sin \left(2 k_{n} d\right)} e^{-k_{n} x} \sin \omega t\right),
\end{gathered}
$$

where $d$ is calm water depth and $k$ is wave number.

Equation (7) has two parts: the first is the incoming wave, and the second part is attenuating standing wave. With the second part of (7) eliminated, surface elevation can be given as follows:

$$
\begin{aligned}
\eta(x, t) & =\frac{X_{0}}{2} \frac{4 \sinh ^{2} k d}{2 k d+\sinh 2 k d} \cos (k x-\omega t) \\
& =\frac{H}{2} \cos (k x-\omega t) .
\end{aligned}
$$

And wave height $H$ can be obtained as follows:

$$
H=\frac{4 \sinh ^{2}(k d)}{2 k d+\sinh (2 k d)} X_{0} .
$$

As mentioned in Section 2.2, to eliminate attenuating standing waves, porous media are employed to form an artificial dissipation zone which is placed at the end of the domain. To model porous media, a momentum source term is added to standard fluid flow equations, which can be given by

$$
S_{i}=-\left(\frac{\mu}{\alpha} v_{i}+C_{2} \frac{1}{2} \rho\left|v_{i}\right| v_{i}\right),
$$

where $S_{i}$ is the source term of momentum equations in $i$ th $(x, y$, or $z)$ direction, $\left|v_{i}\right|$ is the velocity magnitude, $C_{2}$ is the inertial resistance factor, and $\alpha$ is the permeability.

2.4. The Grid of Numerical Model. The 2D numerical tank is a rectangle with $40 \mathrm{~m}$ height, and the length of which is determined by the target waves. The calm water depth $(d)$ is $30 \mathrm{~m}$, and the distance $L_{0}$ between the center of the circular cylinder and the left boundary is $75 \mathrm{~m}$. The numerical grid generated by Gambit is shown in Figure 2 .

A finer mesh can be observed near the free surface for the possibility of wave breaking and near the moving wavemaker, while coarser meshes can be found towards the right wall and the bottom of domain.

\section{Dynamic Results and Analysis}

A commercial CFD software ANSYS Fluent was employed to solve the RANS equation with the free surface capturing VOF scheme and turbulence equations. Setups of models in the present simulations are briefly introduced as follows: georeconstruct scheme, which is the default scheme of the VOF model, is applied to compute the air-water interface (wave surface). For pressure-velocity coupling, the pressure implicit with splitting of operators (PISO) scheme is used, because problems presented in this paper generally involve transient flows. PRESTO! scheme is used for pressure interpolation scheme of VOF two-phase models. The secondorder upwind scheme is applied for discretization of the 


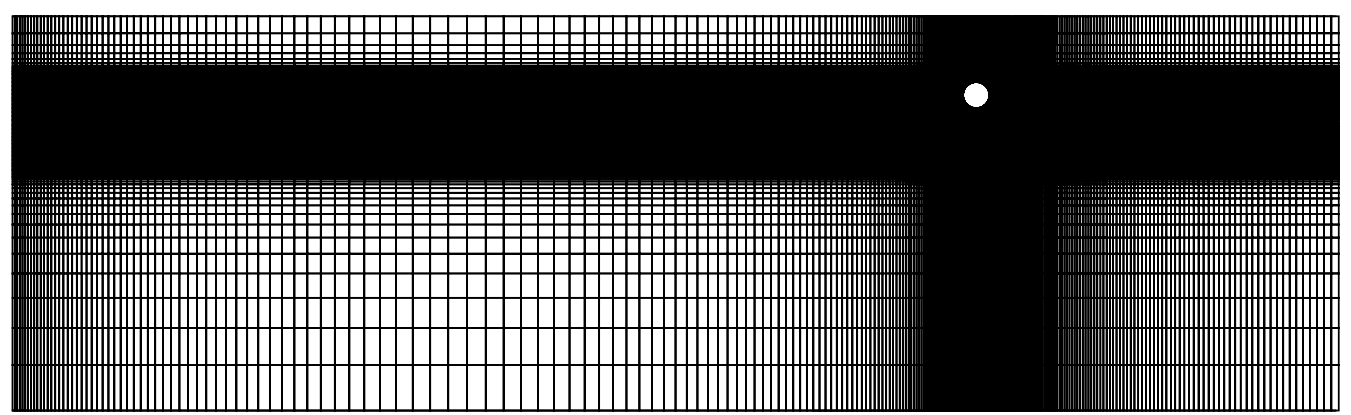

(a) General diagram of mesh

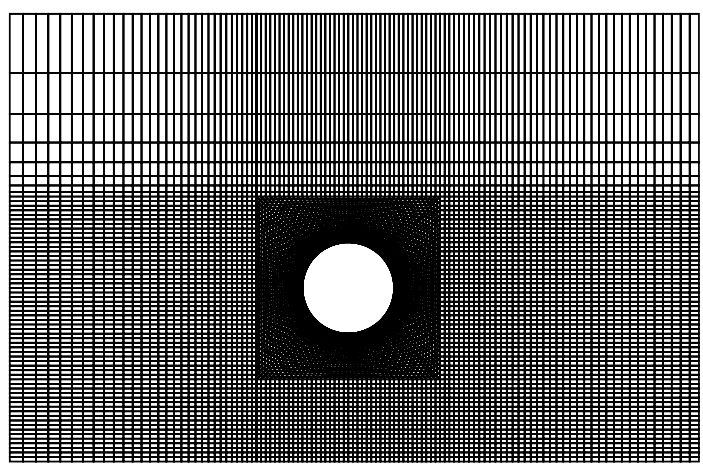

(b) Mesh surrounding moving body

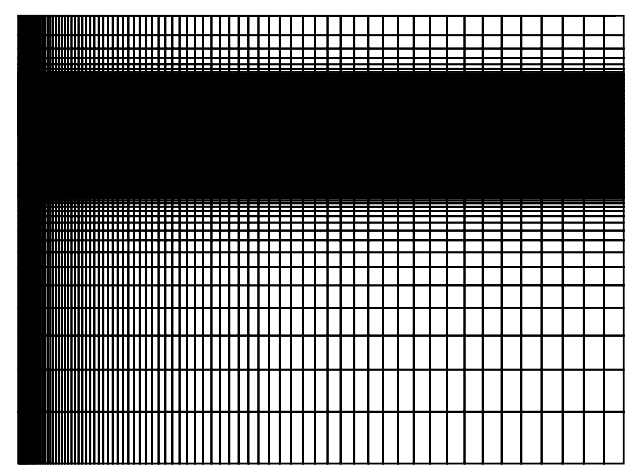

(c) Mesh near the wave-maker

FIgure 2: Schematic diagrams of mesh.

momentum equation to obtain second-order accuracy. As far as the time step size $(\Delta t)$ is concerned, for wave entry problem with constant velocity, which is a typical transient phenomenon, $\Delta t$ can be calculated by

$$
\Delta t \leq C \frac{\Delta x}{v_{f}},
$$

where $C$ is the Courant number, which is set to 0.25 for the VOF model; $\Delta x$ is the minimum cell size; and $v_{f}$ is the maximum characteristic velocity in the fluid domain. For other detailed information, one can refer to manuals of ANSYS Fluent $[23,24]$.

3.1. Numerical Wave Tank. A numerical experiment for simulating a target wave (wave height $=2.5 \mathrm{~m}$, wave period $=$ $6 \mathrm{~s}$ ) is conducted to verify the versatility and correctness of the numerical wave generation and damping methods presented in Section 2. The permeability of porous media in damping zone can be given by

$$
\frac{1}{\alpha(x)}=\alpha_{0}\left(\frac{x-x_{s}}{x_{e}-x_{s}}\right),
$$

where $\alpha_{0}$ is the constant permeability which can be chosen as $1 \times 10^{6} \mathrm{~m}^{2} ; x_{s}$ and $x_{e}$ are starting point coordinate and ending point coordinate of damping zone, respectively; in this paper, $x_{e}=300 \mathrm{~m}$ and $x_{s}=150 \mathrm{~m}$.

Four wave elevation probes are placed at locations of $x=$ $50 \mathrm{~m}, 100 \mathrm{~m}, 200 \mathrm{~m}$, and $300 \mathrm{~m}$ of the numerical wave tank, and the ratio of wave elevations of simulated waves to the wave amplitude of target wave $(\eta / A)$ is employed to evaluate the capability of wave generating and wave absorbing. As shown in Figure 3, for wave elevations in the working zone (locations of $x=50 \mathrm{~m}$ and $100 \mathrm{~m}$ ) of NWT, the amplitude of the ratio $\eta / A$ is approximately equal to $100 \%$, which means that the simulated wave is almost identical with the target wave. In the damping zone (locations of $x=200 \mathrm{~m}$ and $300 \mathrm{~m}$ ), incident waves gradually vanish and at the end of the damping zone $\eta / A$ are less than $5 \%$, which indicates that wave energy is sufficiently dissipated inside the damping zone due to adequate damping capability. Therefore, a conclusion can be drawn that the performance of the NWT can satisfy the need of studying the problem of a circular cylinder lowering through wave zone numerically. It is worth noting that, for the first periods of wave elevations of locations of working zone, the simulated waves are unstable, which can be clearly observed in Figures 3(a) and 3(b); therefore, when the simulated waves are used to study wave-body interaction problem, the first periods need to be avoided.

3.2. Sinking of a Circular Cylinder in Calm Water. To reflect the capability of the presented numerical model to deal with the problem of a body moving near the air-water interface, the example of a circular cylinder sinking in calm water is used. The setup of the numerical model is given below. The radius of the circular cylinder $R$ is $1 \mathrm{~m}$, and the initial distance $h$ between its center and calm water surface is $1.25 \mathrm{~m}$. The gravitational acceleration $g$ is $9.8 \mathrm{~m} / \mathrm{s}^{2}$, and the cylinder moves downwards with a constant velocity $v=1.22 \mathrm{~m} / \mathrm{s}$. 


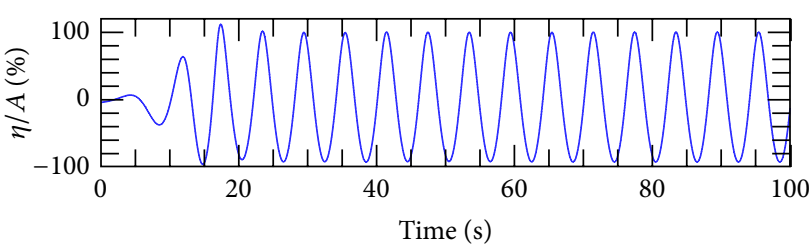

(a)

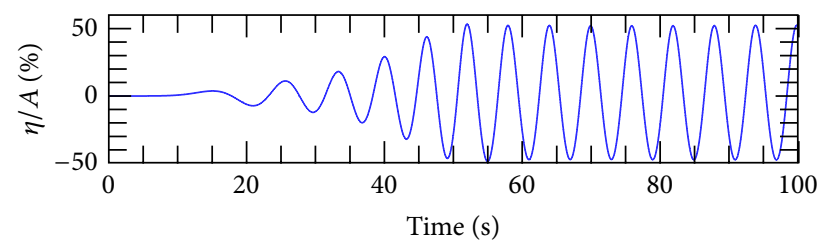

(c)

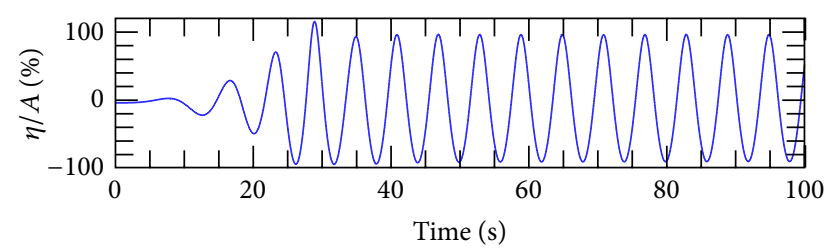

(b)

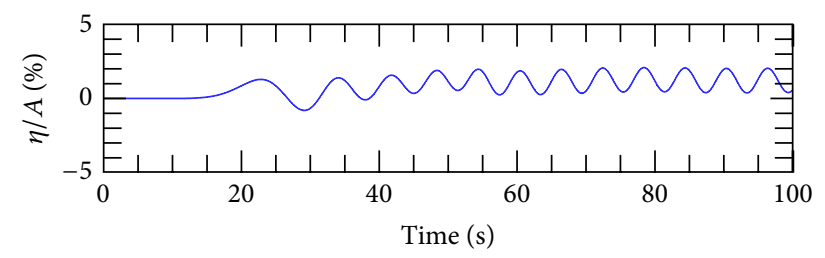

(d)

Figure 3: Wave elevation at four different locations: (a) $x=50 \mathrm{~m}$; (b) $x=100 \mathrm{~m}$; (c) $x=200 \mathrm{~m}$; (d) $x=300 \mathrm{~m}$.

TABLE 1: Mesh sizes used for mesh size study.

\begin{tabular}{lccc}
\hline Mesh size & Number of cells & $\begin{array}{c}\text { Mesh size near the circular } \\
\text { cylinder }\end{array}$ & Mesh size near the free surface \\
\hline Mesh 1 & 26160 & $0.07854 \mathrm{~m}(\pi R / 40)$ & $0.2 \mathrm{~m}(H / 12.5)$ \\
Mesh 2 & 36388 & $0.05236 \mathrm{~m}(\pi R / 60)$ & $0.133 \mathrm{~m}(H / 18.75)$ \\
Mesh 3 & 51590 & $0.03927 \mathrm{~m}(\pi R / 80)$ & $0.1 \mathrm{~m}(H / 25)$ \\
Mesh 4 & 57460 & $0.03142 \mathrm{~m}(\pi R / 100)$ & $0.08 \mathrm{~m}(H / 31.25)$ \\
\hline
\end{tabular}

Parameters mentioned above render Froude number $\mathrm{Fr}=$ $v / \sqrt{g R}=0.39$, relative distance $\varepsilon=h / R=1.25$, and $T=v t / h$, which are the same as those used by Greenhow and Moyo [25] and Lin [26].

Comparisons between free surface profiles of the present model and previous researches, which include Lin's and Greenhow and Moyo's numerical results and Tyvand and Miloh's theoretical results [27], are shown in Figure 4. It is clearly demonstrated that there is a good agreement between results of the present model and previous results, which verifies the effectiveness and accuracy of the numerical model presented in this work.

3.3. Discussion on Mesh Size. The choice of mesh can affect the accuracy of simulation results, computational efficiency, and the solution stability and is dependent on amount of memory available. Therefore, it is important to discuss the size and quality of mesh and choose appropriate meshes. Four different mesh sizes are employed to perform the mesh size study, and main differences between them are sizes of finer meshes near the circular cylinder, the wave-maker, and the free surface, while coarser meshes are basically the same. More information of meshes can be found in Table 1.

Main setups of simulations are as follows: the target wave which is simulated in Section 3.1 is employed; the radius of the circular cylinder $R$ is $1 \mathrm{~m}$; the constant downward velocity of the cylinder $v$ is $1 \mathrm{~m} / \mathrm{s}$; the initial distance between the center of the cylinder and the calm water surface $h$ is $4 \mathrm{~m}$. Besides, the initial time of simulation $t_{0}$ is set as $0 \mathrm{~s}$, and the motion of the wave-maker will generate the target wave since the initial time. The initial time $T_{0}$ when the circular cylinder begins to move downwards is set as $27.684 \mathrm{~s}(T=v t / h=0)$, which means the circular cylinder would impact with the wave surface at $T_{\text {impact }}=30.684 \mathrm{~s}(T=v t / h=0.75)$.

Figure 5 shows time histories of hydrodynamic forces on the circular cylinder. As can be observed from Figure 5, simulation results obtained from the four different mesh sizes are similar. The largest difference can be found at the impact phase, where a finer mesh gives a higher impact force. Furthermore, results of Mesh 3 and Mesh 4 are very close to the value calculated from the equation given by Campbell and Weynberg [28], and the difference between results of Mesh 3 and Mesh 4 is small. Therefore, to obtain a higher computational efficiency and keep accuracy of simulation results, Mesh 3 is used in the following analysis.

\subsection{An Example of the Water Entry of a Circular Cylinder} in Waves. An example is utilized to show the whole water entry process of a circular cylinder in waves, main setups of this numerical example are the same as those described in Section 3.3.

The free surface profiles and pressure distributions at $T=$ $0.75,0.775,0.84,0.9,1.1$, and 1.6 are shown in Figures 6 and 7 , respectively. Figures can demonstrate the water entry and the submergence process of the circular cylinder in waves.

At $T=0.75$, the circular cylinder has already impacts with the wave surface, which indicates that the impact time of simulation is a little earlier than the theoretical impact time due to simulation errors. From Figures 6(a) and 7(a), the following phenomenon can be observed: firstly, pressure 


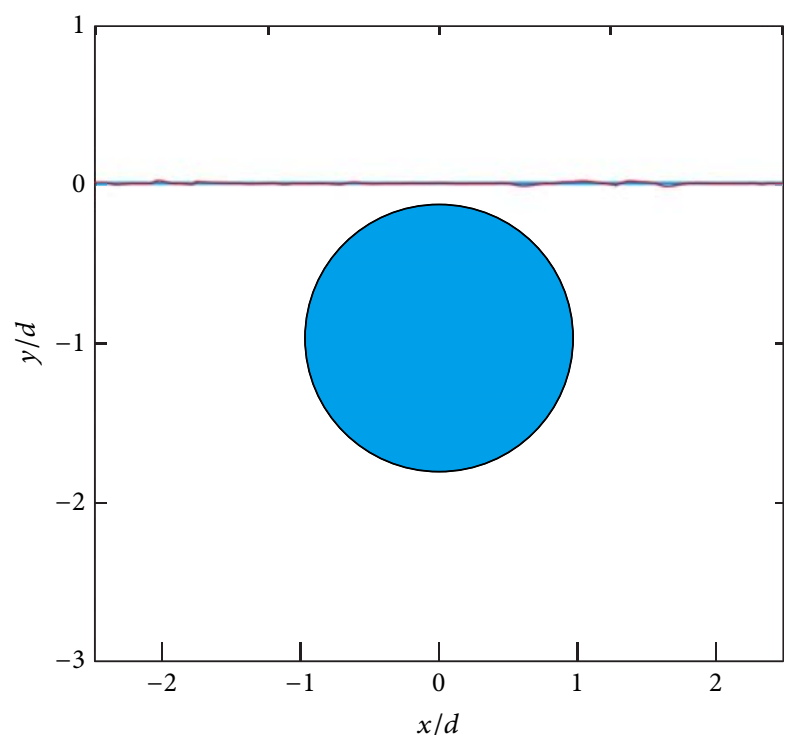

(a) $T=0.0$

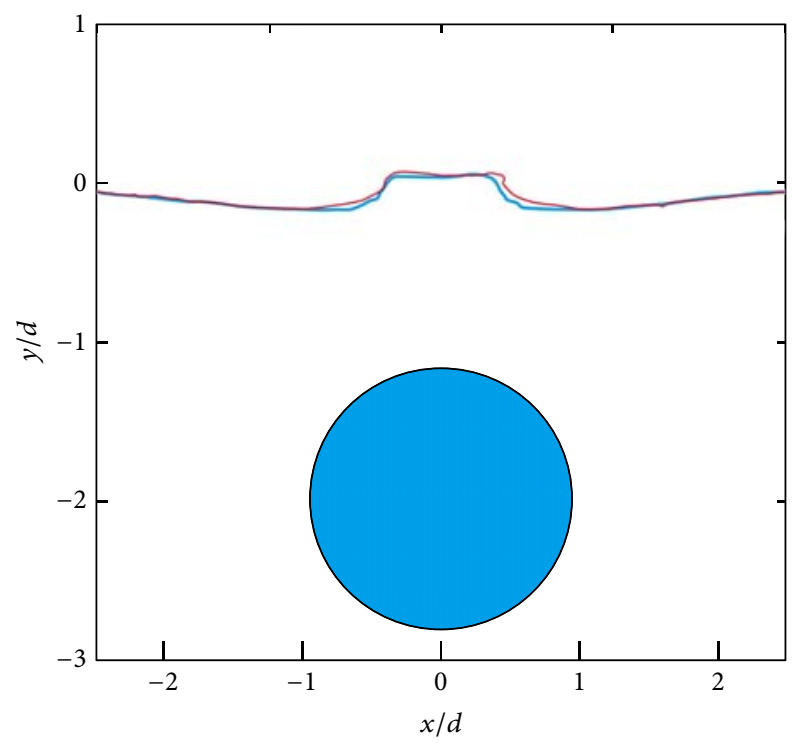

(c) $T=1.0$

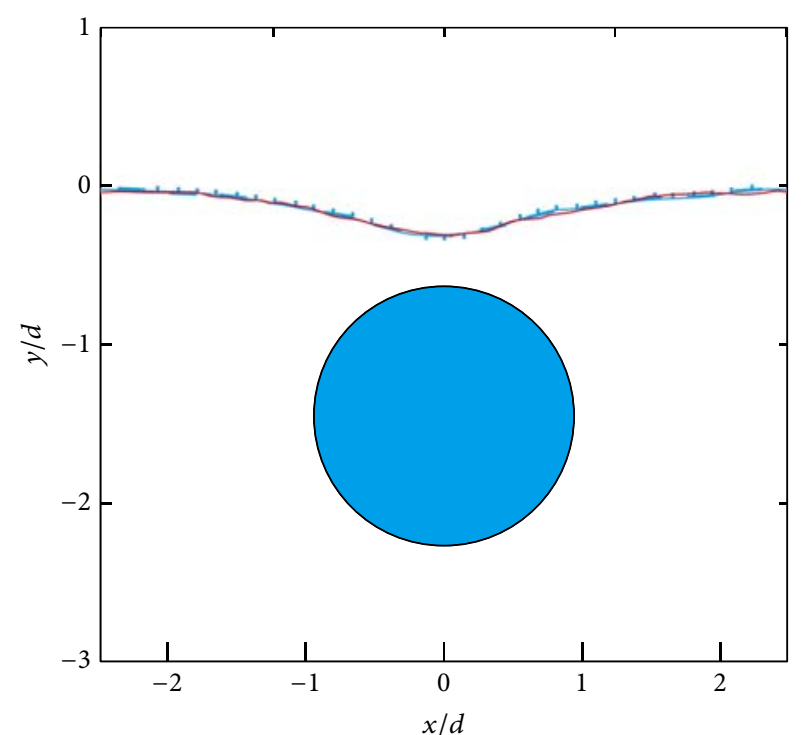

(b) $T=0.4$

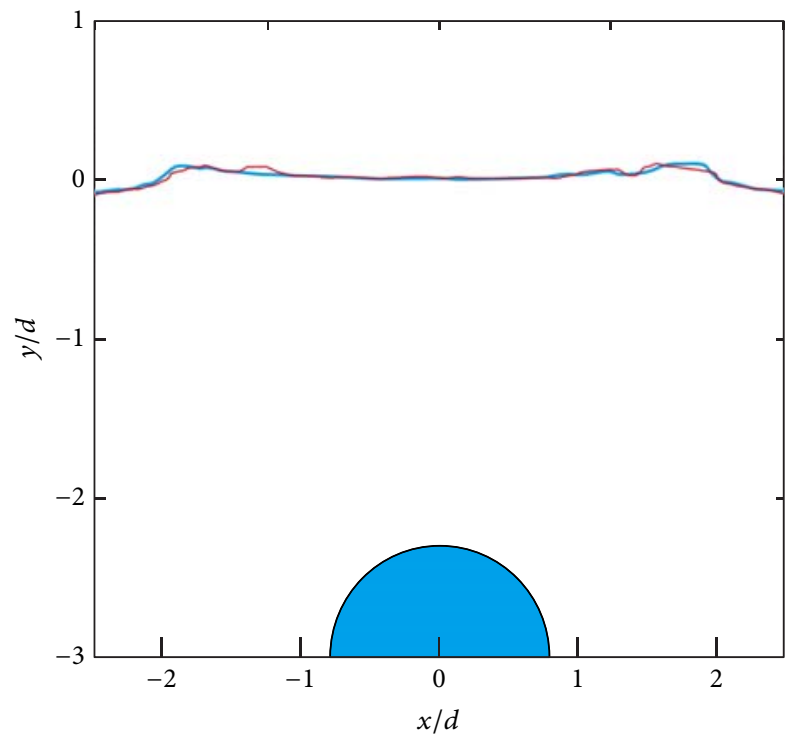

(d) $T=2.0$

FIGURE 4: Comparisons of results by different models of a circular cylinder sinking in calm water: the present results (red solid line); Lin's results (blue solid line); Greenhow et al's results (dashed line); Tyvand et al.s results (dotted line).

distributions on the cylinder are nonsymmetric due to influence of waves; secondly, the peak pressure appears at two contact points between the body and the water-air twophase fluid, and the right peak pressure is bigger than the left one because regular waves travel from the left boundary; besides, the pressure on the bottom point is smaller than that of contact points; thirdly, the pressure on parts of the cylinder getting in contact with water is much bigger than that with air which is approximately equal to zero. The partly immersed state of the circular cylinder at $T=0.775$ is shown in Figures $6(\mathrm{~b})-6(\mathrm{~d})$ and $7(\mathrm{~b})-7(\mathrm{~d})$; a noteworthy feature is the negative pressure that appears at the dry part of the cylinder, which is related to hydroelasticity and needs further research. Figures $6(\mathrm{e})$ and $7(\mathrm{e})$ reflect that the cylinder is almost fully immersed at $T=1.1$, and a zero pressure can be seen at the rigid bodyair-water interface. The fully wet state of the circular cylinder at $T=1.6$ is shown in Figures 6(f) and 7(f), the wave surface deformation above the cylinder can be observed, and the pressure of the lower part is bigger than that of the upper part of the cylinder.

During the transit of a circular cylinder through air-water interface, an important parameter is the vertical hydrodynamic force on the cylinder, also known as the slamming load. The slamming coefficient can be defined, which is the nondimensional impact force:

$$
C_{s}=\frac{F}{\rho V^{2} R}
$$




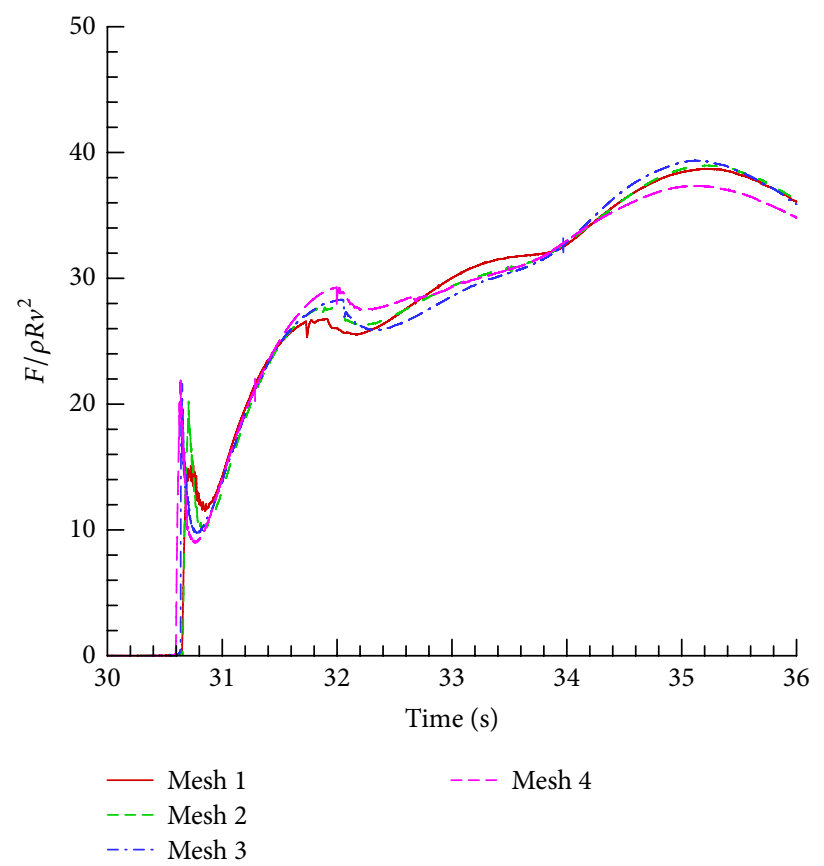

FIGURE 5: Hydrodynamic forces on the circular cylinder with different mesh size.

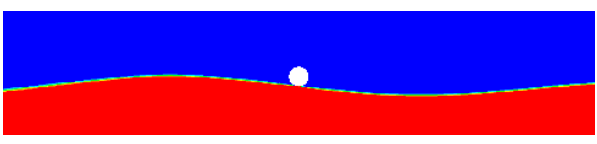

(a)

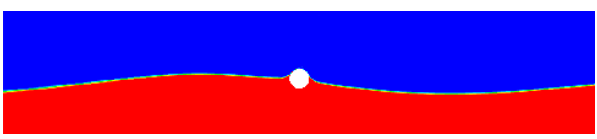

(c)

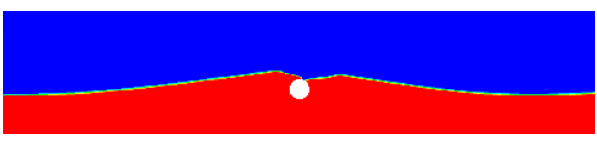

(e)

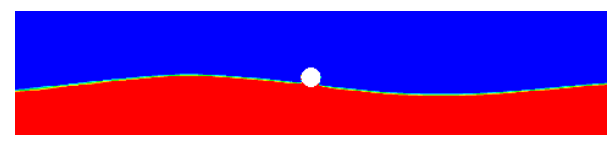

(b)

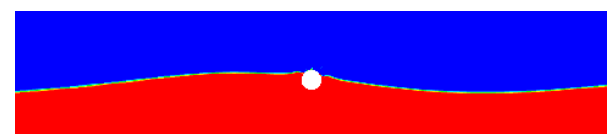

(d)

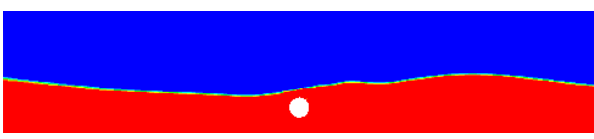

(f)

FIGURE 6: Submergence process of a circular cylinder in waves: (a) $T=0.75$; (b) $T=0.775$; (c) $T=0.84$; (d) $T=0.9$; (e) $T=1.1$; (f) $T=1.6$.

where $F$ is the vertical hydrodynamic force, $V$ is the relative velocity between the cylinder and wave surface, and $R$ is the radius of the cylinder.

When $C_{s}$ is calculated, the theoretical relative velocity is used:

$$
V=v+V_{\text {wave }} \text {, }
$$

where $V_{\text {wave }}$ is the velocity of water particles at the impact time of simulation.

As shown in Figure 8, the time history of slamming coefficient during water entry process of the circular cylinder is compared with experimental results by Miao [29]. The fluctuations observed at the beginning part of simulation results (from $v t / R=0$ to about $v t / R=0.08$ ) are caused by a pressure peak in the spray root that covers a smaller area than the mesh size.

Figure 8 shows that good agreement is obtained between numerical results and experimental data at the initial phase (from $v t / R=0$ to about 0.14 ); however, from $v t / R=$ 0.14 to 1 , the slamming coefficient of numerical results increase rapidly, and the difference between numerical and experimental results also increases accordingly. Two possible explanations for this phenomenon are as follows: firstly, in experimental results by Miao, it is noteworthy that the velocity of the cylinder remains constant during water entry process, while, in the present work, according to (13) and (14), after slamming, the theoretical velocity of water particles $V_{\text {wave }}$ decreases from $v t / R=0$ to 1 , which results in the decrease of relative velocity between the circular cylinder and 


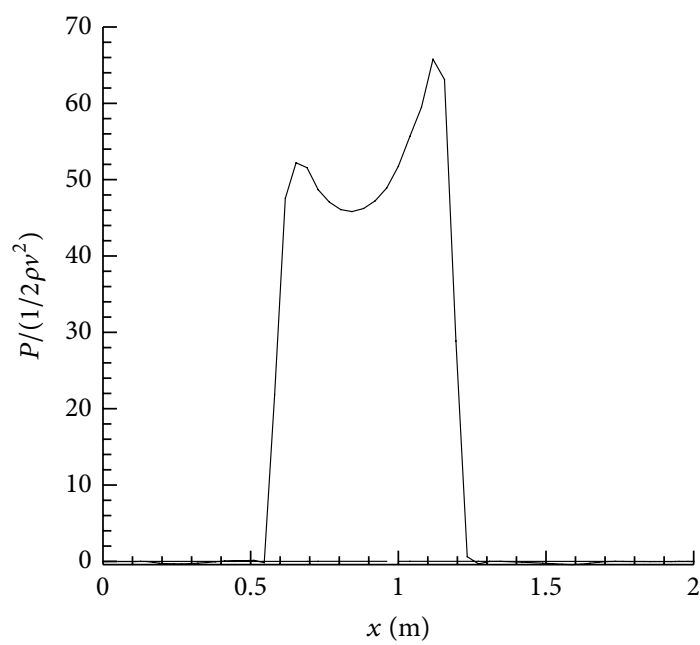

(a)

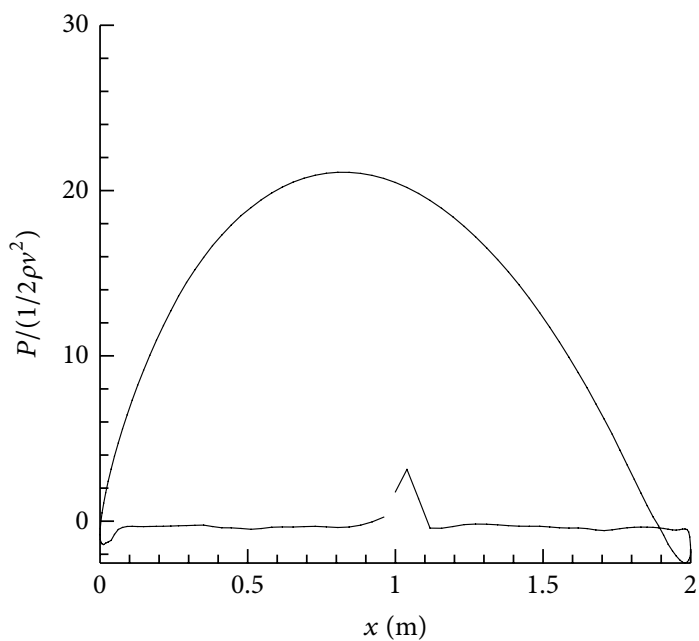

(c)

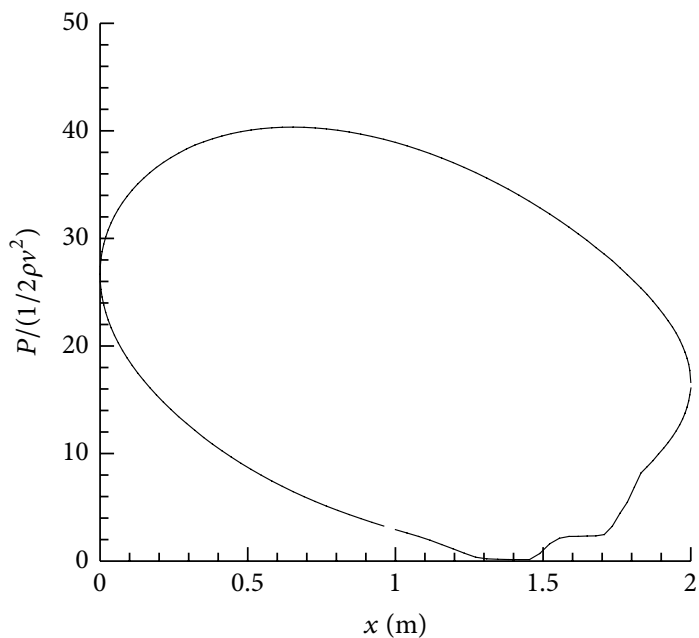

(e)

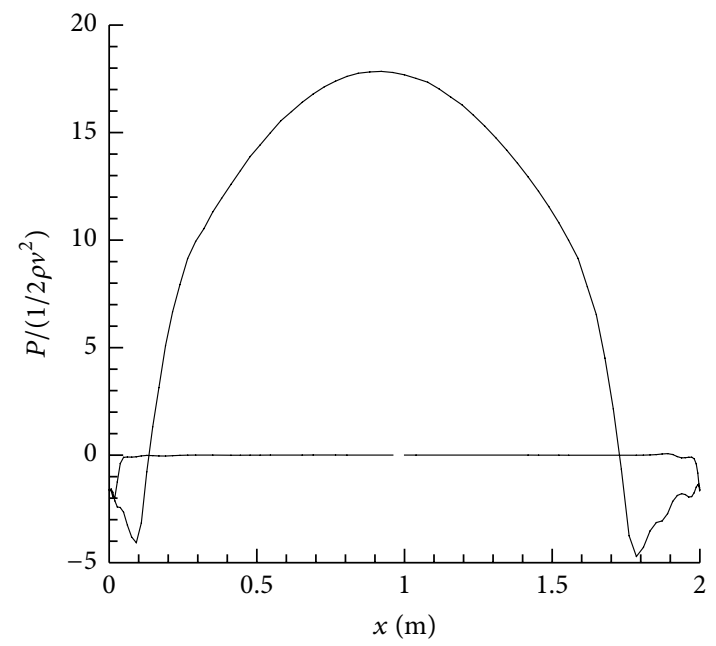

(b)

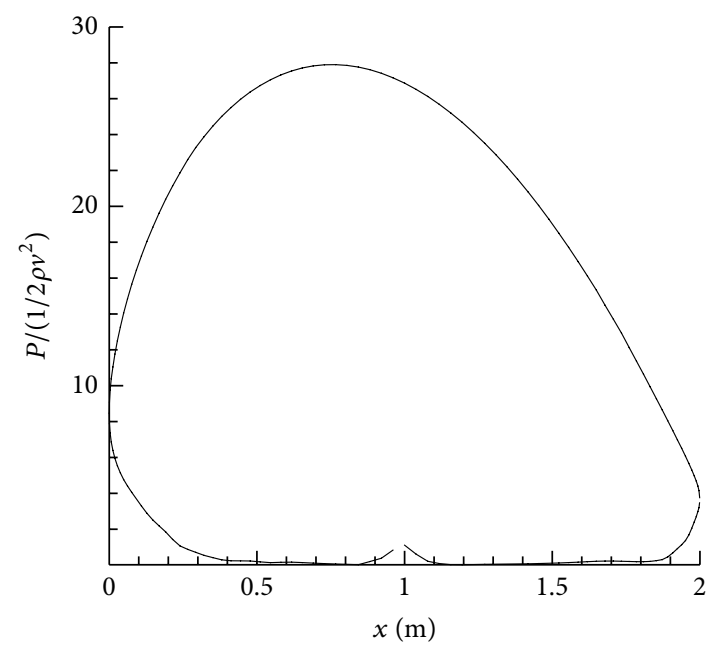

(d)

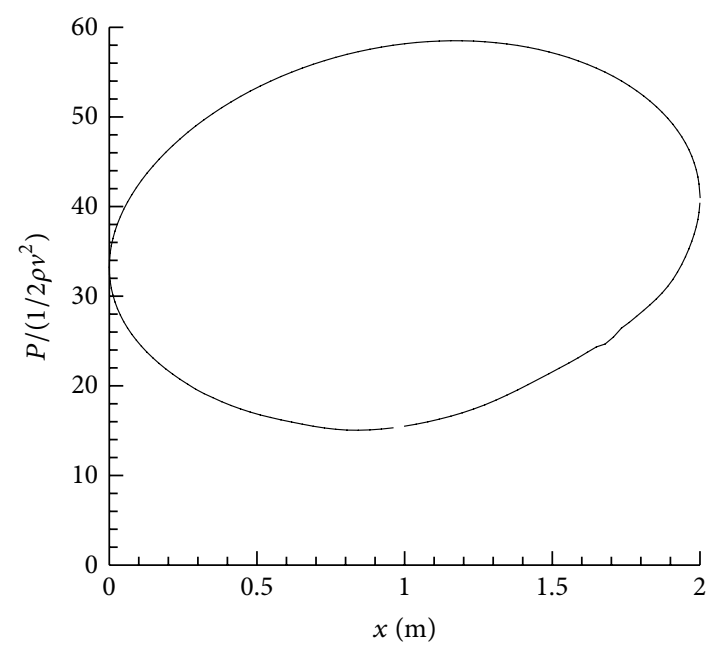

(f)

Figure 7: Pressure distributions on the cylinder: (a) $T=0.75$; (b) $T=0.775$; (c) $T=0.84$; (d) $T=0.9$; (e) $T=1.1$; (f) $T=1.6$. 


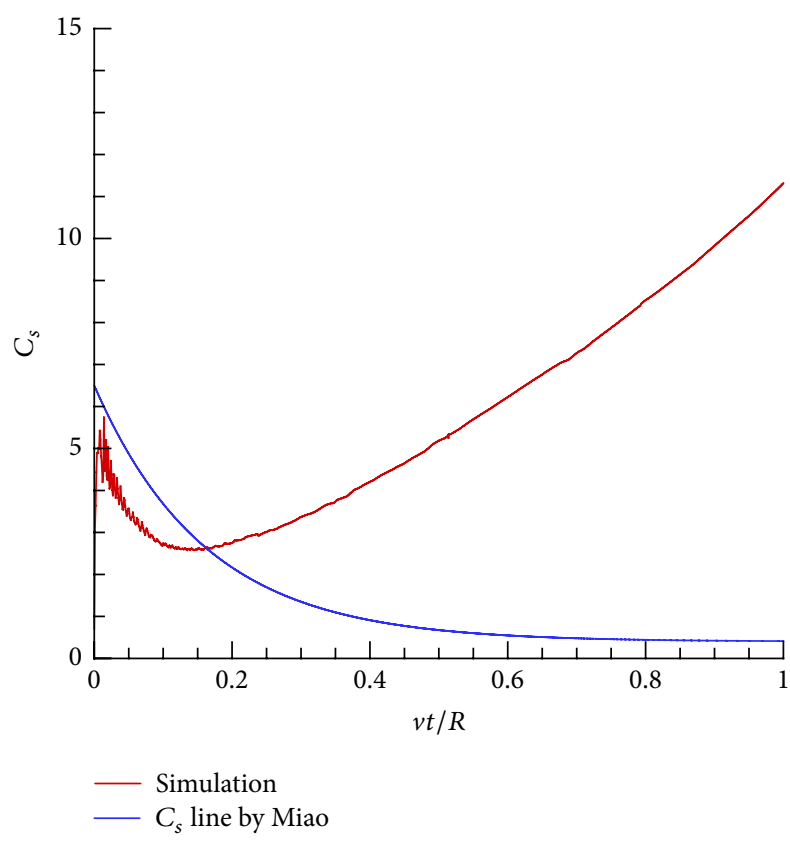

FIgURE 8: Vertical hydrodynamic force on a circular cylinder.

water particles and thus the increase of $C_{s}$. Secondly, the wave surface surrounding circular cylinder varies rapidly and remarkably, which affects the relative velocity between the cylinder and water particles.

3.5. Influence of the Wave Impact Phase Angle. Wave impact phase angles can reflect the relative position between the circular cylinder and wave surface when impact occurs. Figure 9 is a diagram of four typical wave impact phase angles: positions marked as 1,2,3, and 4 are phase angles of $0^{\circ}, 90^{\circ}, 180^{\circ}$, and $270^{\circ}$, respectively.

To investigate the influence of wave impact phase angles, positions marked as $1,2,3$, and 4 shown in Figure 7 are applied. The target wave which is simulated in Section 3.1 is used, and the radius $R$ and the constant vertical velocity $v$ of the circular cylinder are $1 \mathrm{~m}$ and $1 \mathrm{~m} / \mathrm{s}$, respectively.

Two groups of theoretical impact time $T_{\text {impact }}$ which, respectively, correspond to wave impact phase angles of $0^{\circ}$, $90^{\circ}, 180^{\circ}$, and $270^{\circ}$ are as follows:

(1) $30.684 \mathrm{~s}, 26.184 \mathrm{~s}, 27.684 \mathrm{~s}$, and $29.184 \mathrm{~s}$

(2) $36.684 \mathrm{~s}, 32.184 \mathrm{~s}, 33.684 \mathrm{~s}$, and $35.184 \mathrm{~s}$

Obviously, impact times of the second group are obtained by those of first group plus period of wave, $6 \mathrm{~s}$ in this case. Figures 10 (a)-10(d) reflect time histories of fluid forces on the circular cylinder during its lowering through wave surface with different impact phase angles; for the convenience of comparison, figures of the first group are moved to corresponding location of figures of second group with adding $6 \mathrm{~s}$ in time coordinate, named (impact time of the first group $+6 s)$. Figures $11(a)-11(d)$ show velocity vectors near the circular cylinder when the water impact occurs.

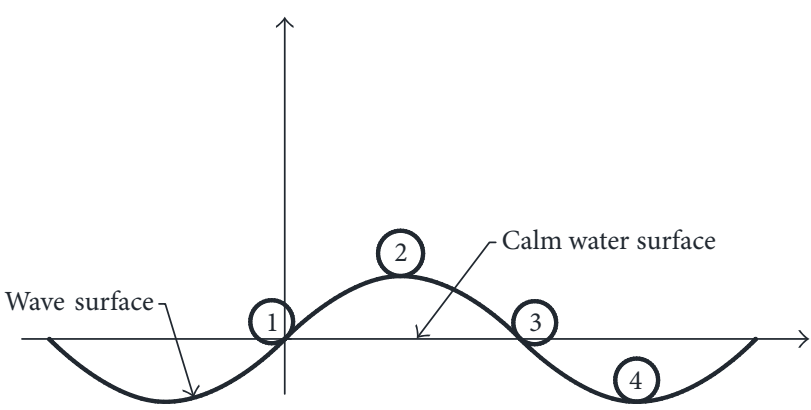

FIGURE 9: Wave impact positions.

TABLE 2: Impact time and maximum hydrodynamic force of different phase angles.

\begin{tabular}{lcccc}
\hline Impact phase angle & $0^{\circ}$ & $90^{\circ}$ & $180^{\circ}$ & $270^{\circ}$ \\
\hline Time of impact $\left(T_{\text {impact }}\right)$ & $36.64 \mathrm{~s}$ & $32.37 \mathrm{~s}$ & $33.68 \mathrm{~s}$ & $35.13 \mathrm{~s}$ \\
Time of $F_{\max }\left(T_{F}\right)$ & $41.18 \mathrm{~s}$ & $36.33 \mathrm{~s}$ & $36.39 \mathrm{~s}$ & $36.8 \mathrm{~s}$ \\
$T_{F}-T_{\text {impact }}$ & $4.56 \mathrm{~s}$ & $3.96 \mathrm{~s}$ & $2.71 \mathrm{~s}$ & $1.67 \mathrm{~s}$ \\
\hline
\end{tabular}

From Figures 10(a)-10(d), the following characteristics can be observed.

Firstly, the simulated impact time is a little earlier or later than the theoretical one, which is due to calculation and simulation error; it is worth noting that no slamming would occur for case of $180^{\circ}$, the main reason of which is that the relative velocity between cylinder and water particles is vertical downwards at the theoretical impact time, which can also be seen in Figure 11(c).

Secondly, the time histories of hydrodynamic forces with the same impact phase angles are mostly identical, which illustrates that smaller impact time can be applied to save simulation time as long as the first wave periods are avoided.

Thirdly, after slamming, the hydrodynamic forces gradually increase to the maximum value for all four phase angles, which is equal to about $40 \mathrm{kN}$, and this phenomenon indicates the impact wave phase exerts no influence on the maximum hydrodynamic force; considering the length of the time interval between impact time $T_{\text {impact }}$ and time $T_{F}$ of which the maximum hydrodynamic force appears, it varies with phase angles, which are shown in Table 2. It can be seen that the interval length decreases with phase angle increasing from $0^{\circ}$ to $270^{\circ}$.

Fourthly, after it reaches the maximum value, the hydrodynamic force oscillates near an equilibrium point about $31 \mathrm{kN}$, which is equal to the buoyancy of the circular cylinder, and the oscillation period is about $6 \mathrm{~s}$, which is equal to period of the target wave; besides, as simulation time goes on, the oscillation amplitude is smaller and smaller and hopefully becomes zero eventually, mainly because of the fact that wave effect becomes smaller with water depth increasing.

As far as the slamming force are concerned, cases with phase angle $0^{\circ}$ have the biggest one, which is also the most dangerous situation for cylinder lowering through wave surface, mainly due to the biggest relative velocity between the cylinder and water particles, which can be observed from 


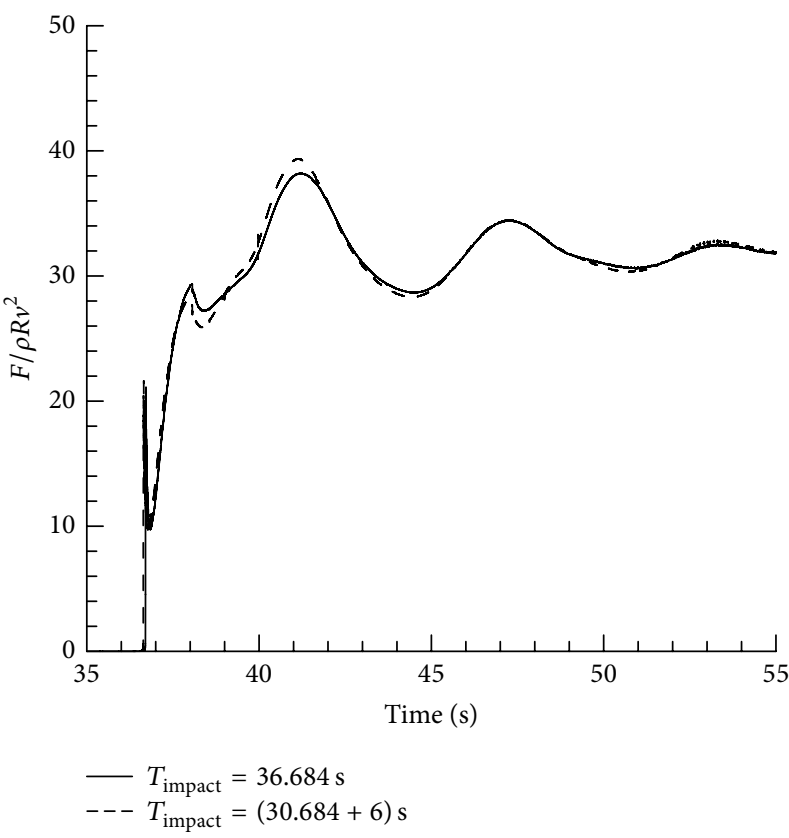

(a)

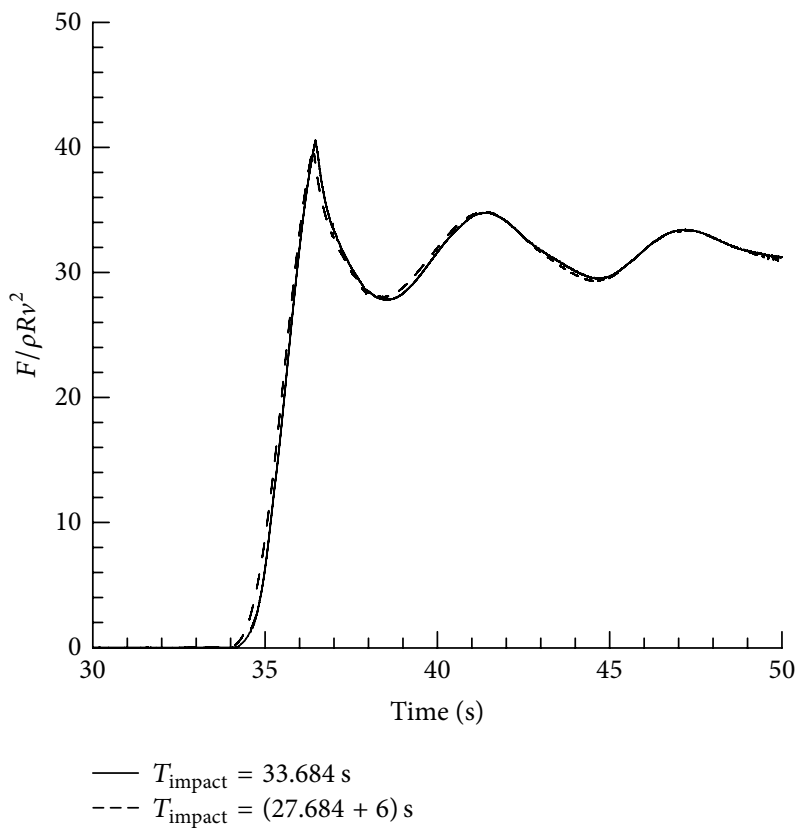

(c)

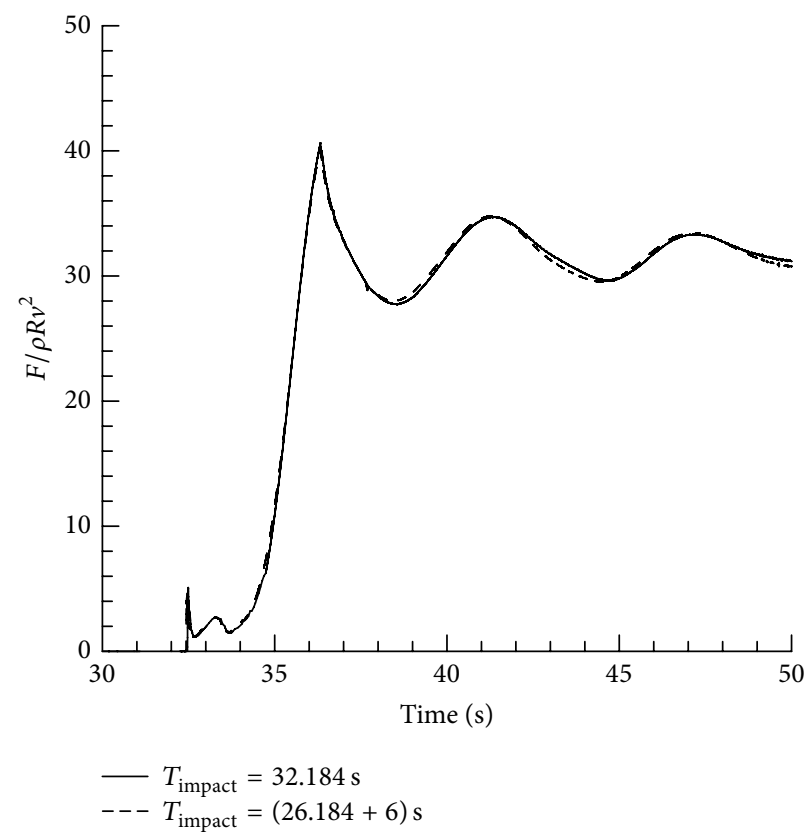

(b)

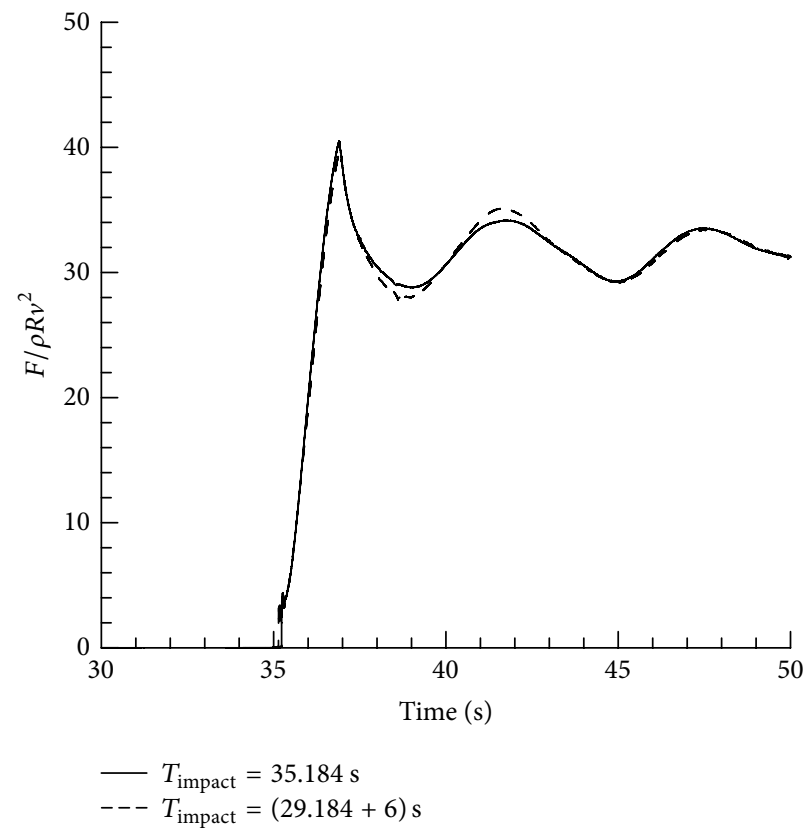

(d)

Figure 10: Time history of hydrodynamic force with different impact phase angles: (a) $0^{\circ}$; (b) $90^{\circ}$; (c) $180^{\circ}$; (d) $270^{\circ}$.

Figure 11. Therefore, in the following sections, only phase angle $0^{\circ}$ is used to investigate the effect of other parameters.

3.6. Influence of the Wave Height. In order to study the influence of the wave height, time histories of hydrodynamic force with five different wave heights of regular waves, $1.7 \mathrm{~m}, 2 \mathrm{~m}$, $2.3 \mathrm{~m}, 2.6 \mathrm{~m}$, and $3 \mathrm{~m}$, are considered; other parameters are as follows: impact phase angle $=0^{\circ}$, wave period $=6 \mathrm{~s}$, constant velocity of the circular cylinder $v=1 \mathrm{~m} / \mathrm{s}$, and cylinder radius $R=1 \mathrm{~m}$.
From Figure 12, the following phenomena can be observed: firstly, for all five wave heights, hydrodynamic forces have the similar trends and characteristics: after impacting with wave surface, the forces increase to maximum values and then oscillate near the buoyancy of the circular cylinder with oscillation period equaling the wave periods, and the oscillation amplitude would eventually be zero; secondly, both impact forces and maximum hydrodynamic forces increase with an increase of the wave height, and the oscillation amplitude of curves have the similar tendency; 


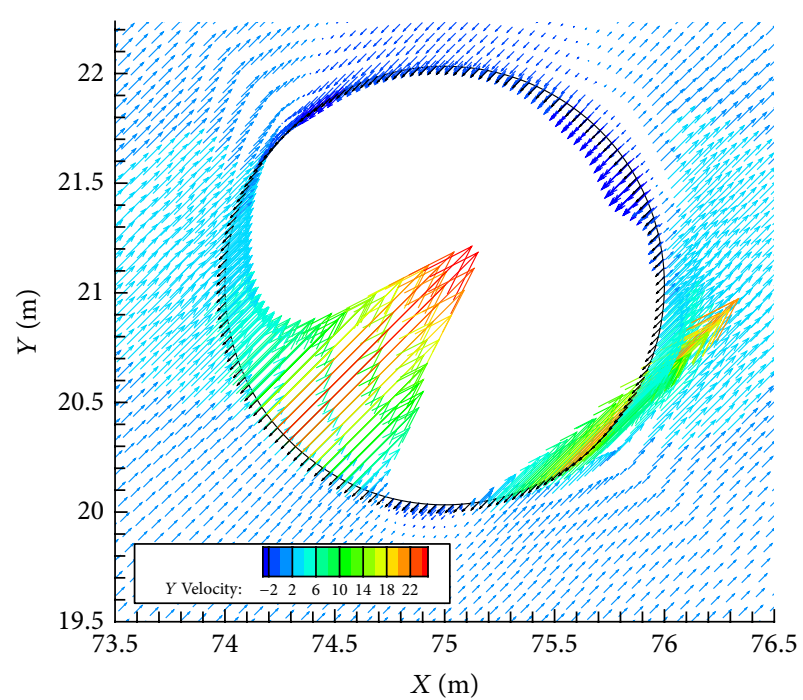

(a)

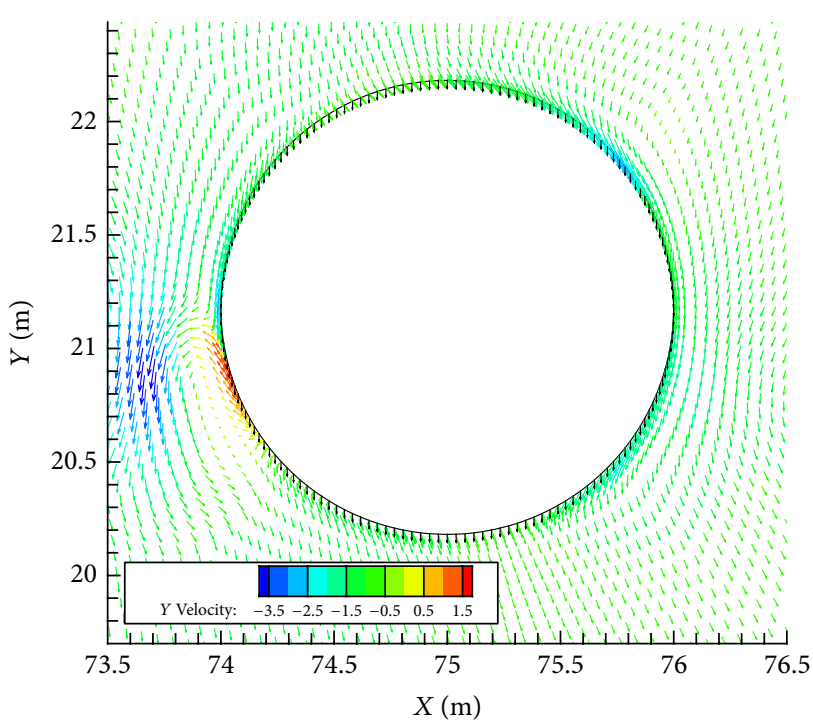

(c)

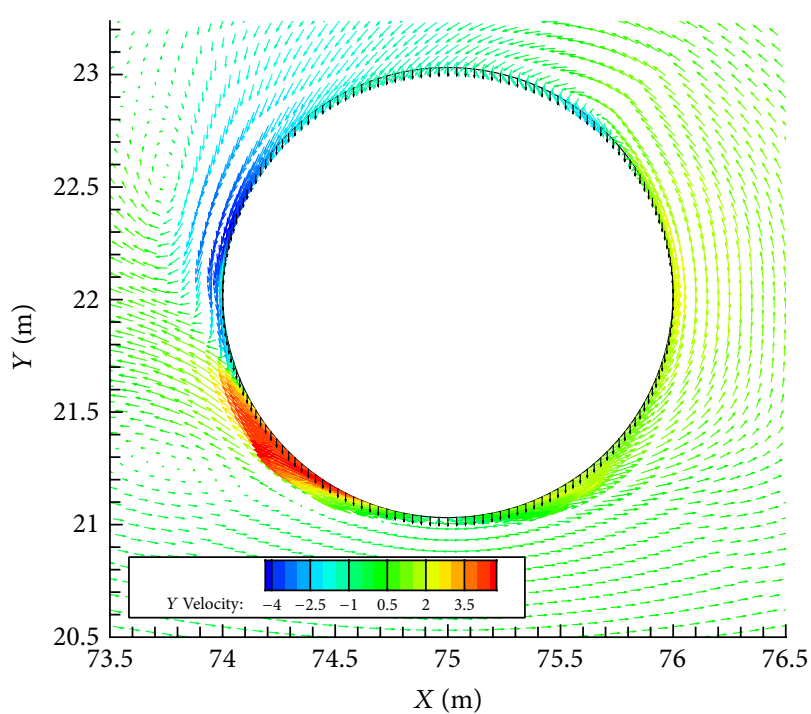

(b)

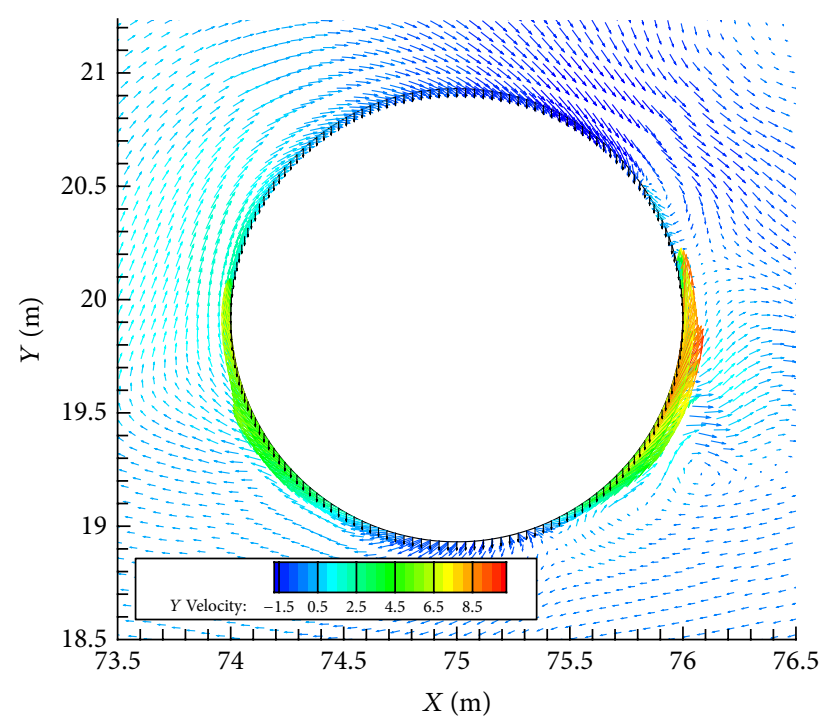

(d)

FIGURE 11: Velocity vectors when water impact occurs with different impact phase angles: (a) $0^{\circ}$; (b) $90^{\circ}$; (c) $180^{\circ}$; (d) $270^{\circ}$.

thirdly, the lengths of time interval between $T_{\text {impact }}$ and $T_{F}$ are the same for different wave heights with equivalent wave periods.

3.7. Influence of the Wave Period. In order to investigate the influence of the wave period, time histories of fluid forces with five different wave periods of regular waves, $5 \mathrm{~s}, 6 \mathrm{~s}, 7 \mathrm{~s}$, $8 \mathrm{~s}$, and $9 \mathrm{~s}$, are considered, which are shown in Figure 13; other parameters are as follows: impact phase angle $=0^{\circ}$, wave height $=2 \mathrm{~m}$, constant velocity of the circular cylinder $v=1 \mathrm{~m} / \mathrm{s}$, and cylinder radius $R=1 \mathrm{~m}$.

The following phenomena can be seen from Figure 13: firstly, both the impact force and the oscillation amplitude of fluid force curves increase with a decrease of wave period. Secondly, hydrodynamic forces oscillate near the buoyancy of the circular cylinder, and oscillation periods are equal to the wave periods. Thirdly, for cases with periods equaling $8 \mathrm{~s}$ and $9 \mathrm{~s}$, it is worth noting that the first peak force is the maximum hydrodynamic force, which is different from other cases, and first peak forces of all cases increase with an increase of periods.

3.8. Influence of the Froude Number. For the circular cylinder that is moving through wave surface, the Froude number $F_{n}$ is an important dimensionless number, which is dependent on vertical velocity and radius of the cylinder. To study the effect of the Froude number on wave impact loads, two group simulations are performed. The first group uses different radiuses, parameters of which are as follows: $R=1 \mathrm{~m}, 0.8 \mathrm{~m}$, and $0.5 \mathrm{~m}$; impact phase angle $=0^{\circ}$; wave height $=2 \mathrm{~m}$; wave period $=6 \mathrm{~s}$; constant velocity of the circular cylinder $v=$ $1 \mathrm{~m} / \mathrm{s}$, which render $F_{n}=0.45,0.36$, and 0.32 . The second 


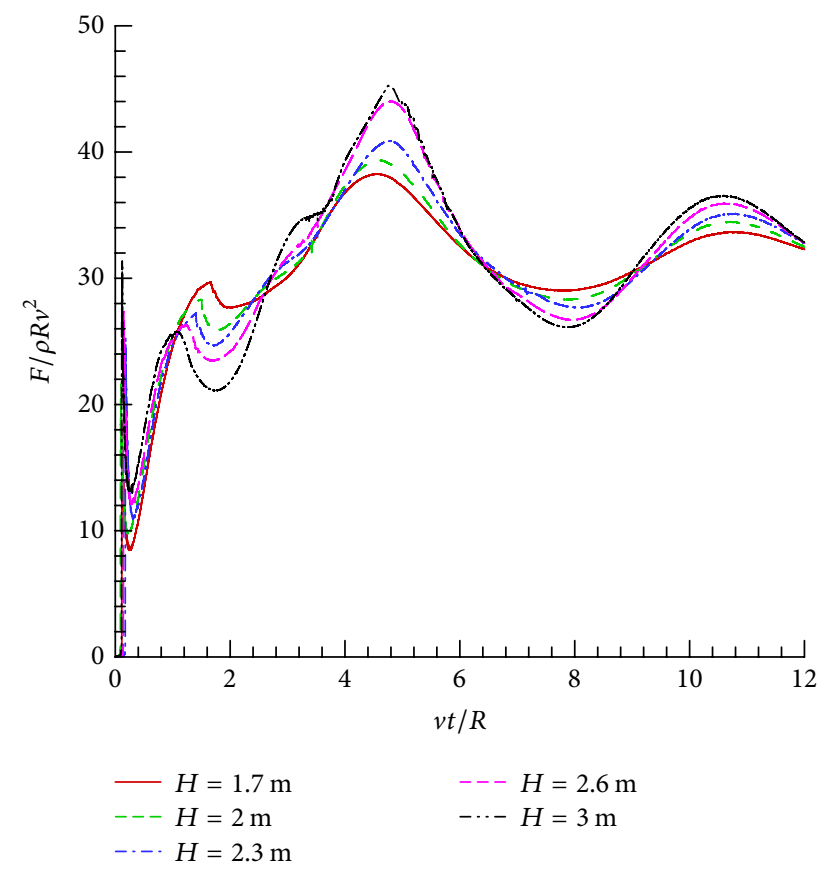

FIGURE 12: Fluid forces with different wave heights.

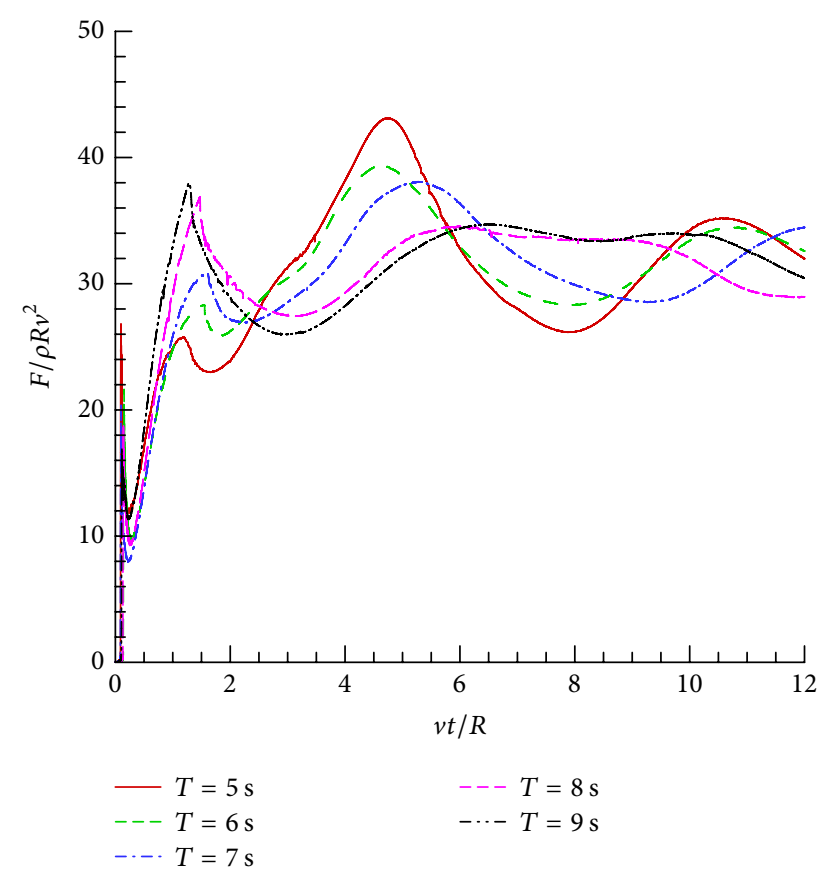

Figure 13: Fluid forces with different wave periods.

group uses different velocities, and their parameters are as follows: $R=0.5 \mathrm{~m}$; impact phase angle $=0^{\circ}$; wave height $=2 \mathrm{~m}$; wave period $=6 \mathrm{~s}$; constant velocity of the circular cylinder $v$ $=1,2$, and $3.5 \mathrm{~m} / \mathrm{s}$, which render $F_{n}=0.45,0.9$, and 1.575 .

Figure 14 shows hydrodynamic load on cylinders with different radiuses during the submergence process. In this figure, it can be seen that the nondimensional hydrodynamic load $F /\left(\rho R v^{2}\right)$ increases as the radius of the cylinder becomes

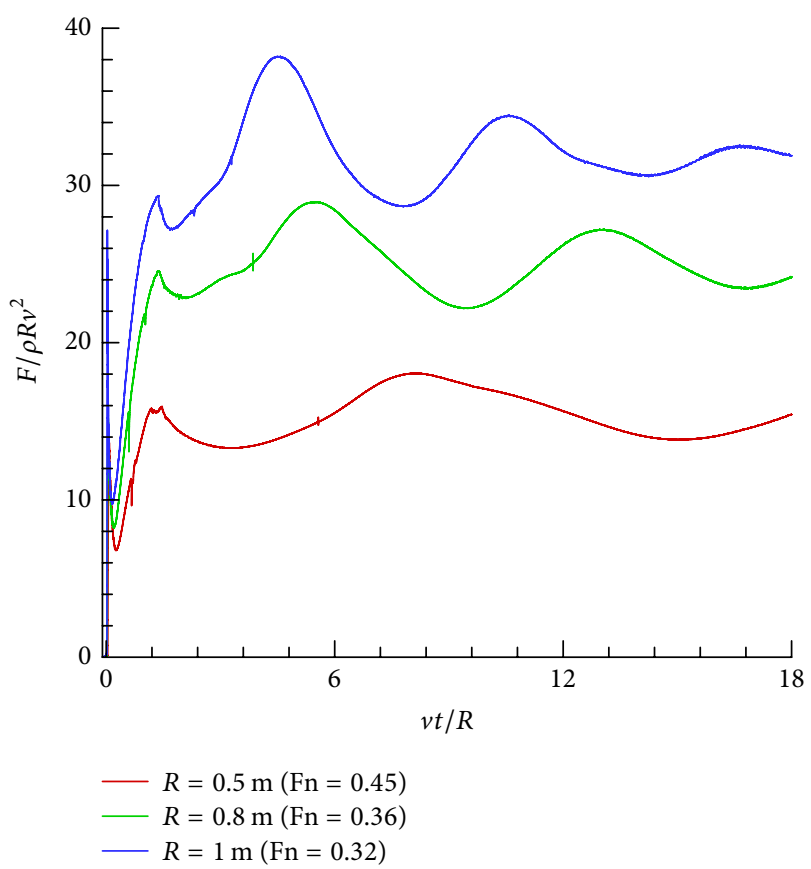

Figure 14: Fluid forces with different cylinder radiuses.

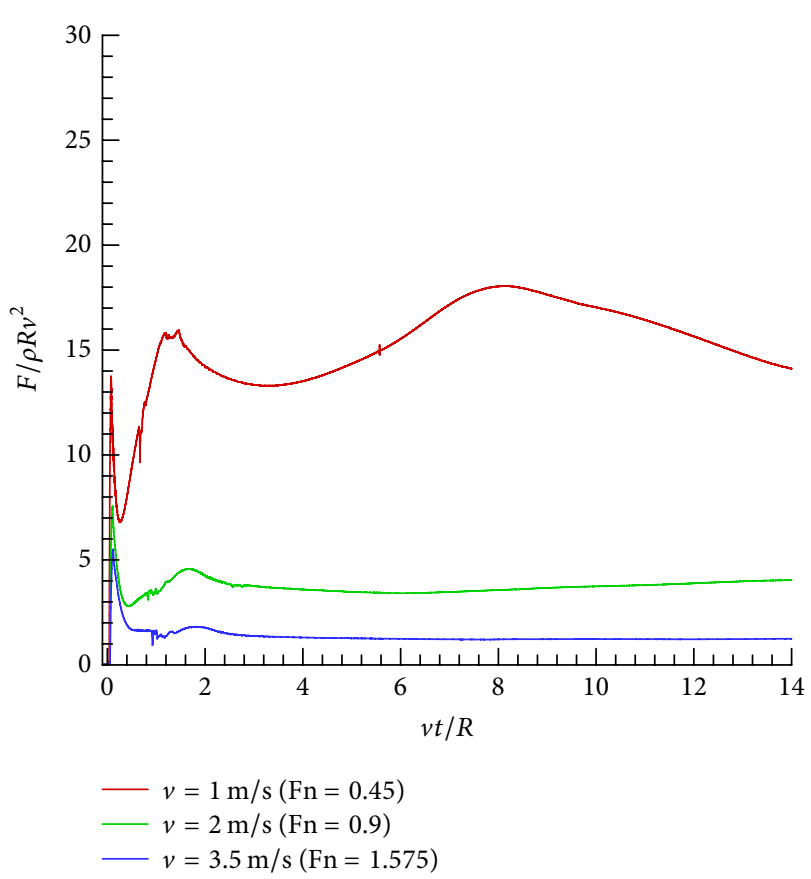

FIGURE 15: Fluid forces with different vertical velocities.

bigger and oscillates near respective buoyancies of cylinders with different radiuses. Figure 15 presents the time histories of hydrodynamic load $F /\left(\rho R v^{2}\right)$ with different constant velocities. It is seen that fluid forces increase with velocities of the cylinder decrease. From Figures 14 and 15, it can also be seen that the nondimensional slamming forces (the first peak force) increase with decreasing Froude number $F_{n}$, the 
main reason is that the smaller the Froude number, the more remarkable the wave exerting influence.

\section{Conclusions}

(1) After the cylinder impacting with wave surface, the forces increase to some maximum value and then oscillate near the buoyancy of the cylinder with oscillation period equaling the wave periods, and the oscillation amplitude would eventually be zero.

(2) On one hand, cases with wave impact angle $0^{\circ}$ and $180^{\circ}$, respectively, have the biggest and smallest impact forces, and cases with other wave impact angles lie within the range. For another hand, wave impact angle exerts no influence on the maximum hydrodynamic force during the submergence process.

(3) Both the impact force and maximum hydrodynamic force increase with an increase of wave heights, while both of them increase with a decrease of wave periods, which is due to the influence of the relative velocity between the cylinder and water particles.

(4) The hydrodynamic force is also largely affected by cylinder radius and constant velocity; the nondimensional slamming force decreases with an increase of the Froude number.

\section{Conflicts of Interest}

The authors declare that there are no conflicts of interest regarding the publication of this paper.

\section{Acknowledgments}

The authors gratefully acknowledge the financial support of Natural Science Foundation of Hunan Province of China (Grant no. 2017JJ3393), the National Natural Science Foundation of China (no. 51305463), and the National Key Research and Development Plan of China (no. 2016YFC0304103).

\section{References}

[1] V. Karman, "The impact of seaplane floats during landing," ational Advisory Committee for Aeronautics, pp. 1-8, 1929.

[2] H. Wanger, "Trans phenomena associated with impacts and sliding on liquid surfaces," Journal of Applied Mathematics and Mechanics, vol. 12, no. 4, pp. 193-215, 1932.

[3] M. Greenhow, "Water-entry and-exit of a horizontal circular cylinder," Applied Ocean Research, vol. 10, no. 4, pp. 191-198, 1988.

[4] X. M. Mei, Y. M. Liu, and D. K. P. Yue, "On the water impact of general two-dimensional sections," Applied Ocean Research, vol. 21, no. 1, pp. 1-15, 1999.

[5] H. Sun, A Boundary Element Method Applied to Strongly Nonlinear Wave-Body Interaction Problems [Ph.D. thesis], Norwegian University of Science and Technology, Trondheim, Norway, 2007.

[6] X. Zhu, Application of the CIP Method to Strongly Nonlinear Wave-Body Interaction Problems [Ph.D. thesis], Norwegian University of Science and Technology, Trondheim, Norway, 2006.
[7] Q. Yang and W. Qiu, "Numerical simulation of water impact for 2D and 3D bodies," Ocean Engineering, vol. 43, pp. 82-89, 2012.

[8] K. Zhang, K. Yan, X.-S. Chu, and G.-Y. Chen, "Numerical simulation of the water-entry of body based on the Lattice Boltzmann method," Journal of Hydrodynamics, vol. 22, no. 5, pp. 829-833, 2010.

[9] J. Vandamme, Q. Zou, and D. E. Reeve, "Modeling floating object entry and exit using smoothed particle hydrodynamics," Journal of Waterway, Port, Coastal, and Ocean Engineering, vol. 137, no. 5, pp. 213-224, 2011.

[10] A. Skillen, S. Lind, P. K. Stansby, and B. D. Rogers, "Incompressible smoothed particle hydrodynamics $(\mathrm{SPH})$ with reduced temporal noise and generalised Fickian smoothing applied to body-water slam and efficient wave-body interaction," Computer Methods Applied Mechanics and Engineering, vol. 265, pp. 163-173, 2013.

[11] H. B. Gu, L. Qian, D. M. Causon, C. G. Mingham, and P. Lin, "Numerical simulation of water impact of solid bodies with vertical and oblique entries," Ocean Engineering, vol. 75, pp. 128137, 2014.

[12] V.-T. Nguyen, D.-T. Vu, W.-G. Park, and C.-M. Jung, "NavierStokes solver for water entry bodies with moving Chimera grid method in 6DOF motions," Computers and Fluids, vol. 140, pp. 19-38, 2016.

[13] W. Peng and Q. Wei, "Solving 2-D water entry problems with a CIP method and a parallel computing algorithm," Marine Systems Ocean Technology, vol. 11, no. 1-2, p. 1, 2016.

[14] A. Iranmanesh and M. Passandideh-Fard, "A three-dimensional numerical approach on water entry of a horizontal circular cylinder using the volume of fluid technique," Ocean Engineering, vol. 130, pp. 557-566, 2017.

[15] P. Nair and G. Tomar, "A study of energy transfer during water entry of solids using incompressible SPH simulations," Sädhanā, vol. 42, no. 4, pp. 517-531, 2017.

[16] F. Aristodemo, G. Tripepi, D. D. Meringolo, and P. Veltri, "Solitary wave-induced forces on horizontal circular cylinders: laboratory experiments and SPH simulations," Coastal Engineering Journal, vol. 129, pp. 17-35, 2017.

[17] C. Mnasri, Z. Hafsia, M. Omri, and K. Maalel, "A moving grid model for simulation of free surface behavior induced by horizontal cylinders exit and entry," Engineering Applications of Computational Fluid Mechanics, vol. 4, no. 2, pp. 260-275, 2014.

[18] Y. Chen, Y. Gao, and Q. Liu, "Numerical simulation of waterentry in a horizontal circular cylinder using the volume of fluid (VOF) method," Journal of Harbin Engineering University, vol. 32, no. 11, pp. 1439-1442, 2011.

[19] P. Ghadimi, A. Dashtimanesh, and S. R. Djeddi, "Study of water entry of circular cylinder by using analytical and numerical solutions," Journal of the Brazilian Society of Mechanical Sciences \& Engineering, vol. 34, no. 3, pp. 225-232, 2012.

[20] A. Tassin, D. J. Piro, A. A. Korobkin, K. J. Maki, and M. J. Cooker, "Two-dimensional water entry and exit of a body whose shape varies in time," Journal of Fluids and Structures, vol. 40, pp. 317336, 2013.

[21] E. Larsen, Impact Loads on Circular Cylinders, Norwegian University of Science and Technology, Trondheim, Norway, 2013.

[22] B. E. Launder and D. B. Spalding, Lectures in Mathematical Models of Turbulence, Academic Press, London, UK, 1972.

[23] ANSYS, ANSYS Fluent User's Guide, 2013.

[24] ANSYS, ANSYS Fluent Theory Guide, 2013. 
[25] M. Greenhow and S. Moyo, "Water entry and exit of horizontal circular cylinders," Philosophical Transactions of the Royal Society of London. Series A. Mathematical, Physical Sciences and Engineering, vol. 355, no. 1724, pp. 551-563, 1997.

[26] P. Lin, "A fixed-grid model for simulation of a moving body in free surface flows," Computers \& Fluids, vol. 36, no. 3, pp. 549561, 2007.

[27] P. A. Tyvand and T. Miloh, "Free-surface flow due to impulsive motion of a submerged circular cylinder," Journal of Fluid Mechanics, vol. 286, pp. 67-101, 1995.

[28] T. Campbell and P. Weynberg, "Measurement of parameters affecting slamming - final report," Tech. Rep. 440, Wolfson Marine Craft Unit, University of Southampton, 1980.

[29] G. Miao, Hydrodynamic forces and dynamic responses of circular cylinders in wave zones [Ph.D. thesis], Dept. of Marine Hydrodynamics, Trondheim, Norway, 1989. 


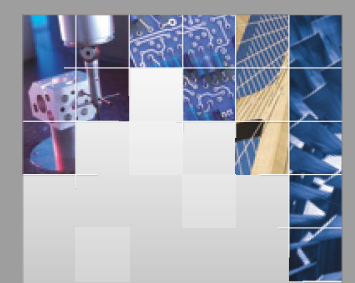

\section{Enfincering}
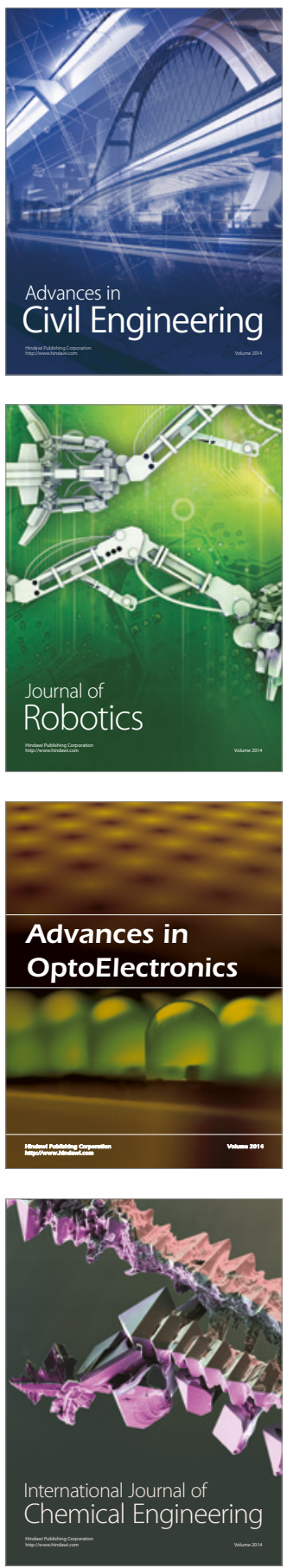

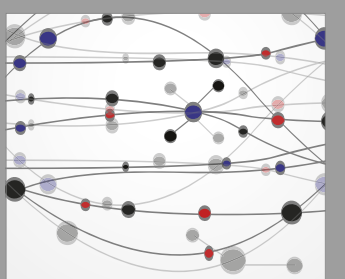

The Scientific World Journal

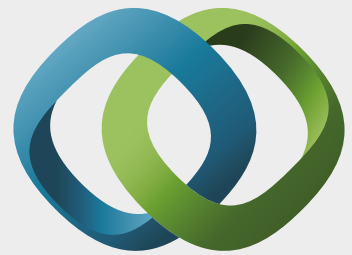

\section{Hindawi}

Submit your manuscripts at

https://www.hindawi.com
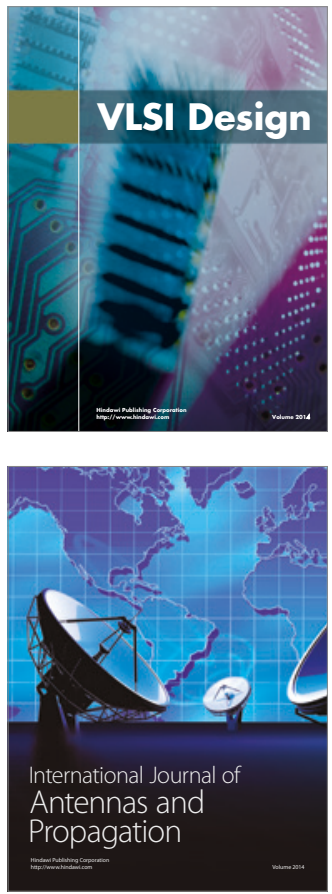

\section{Rotating}

Machinery
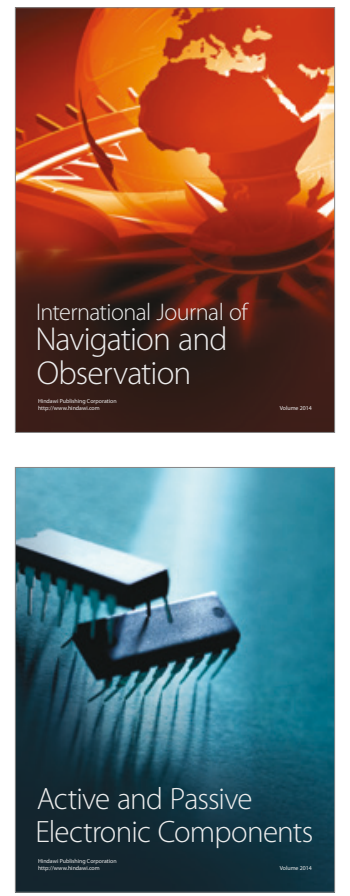
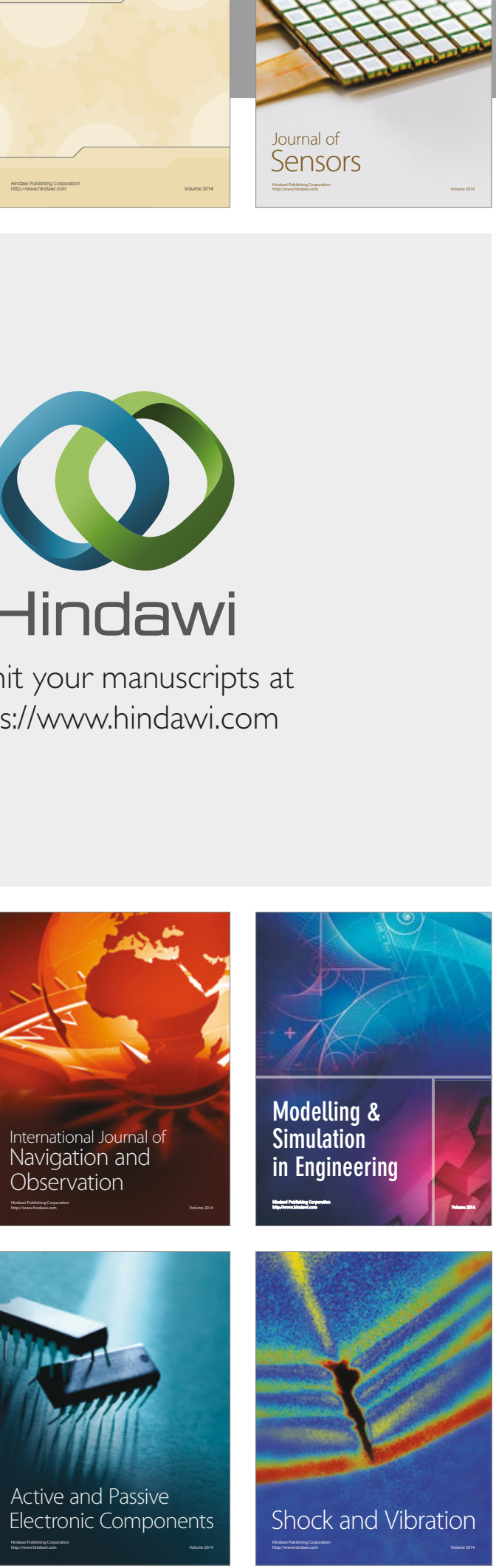
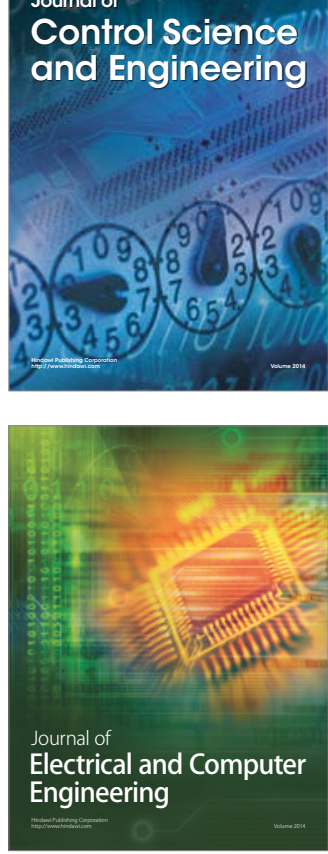

Distributed

Journal of

Control Science

and Engineering
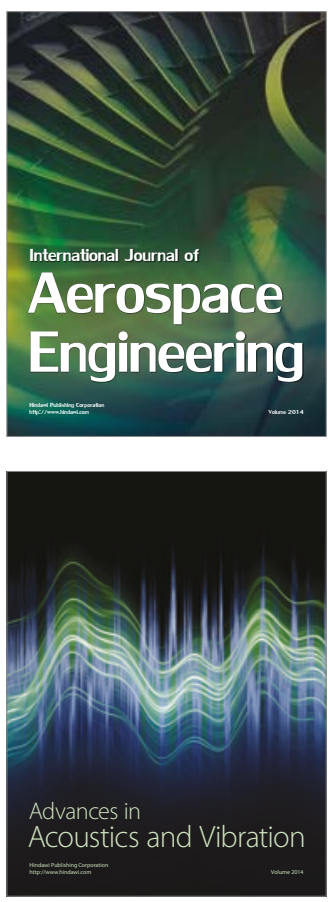

Sensor Networks 